\title{
Der Wurzener Geschichts- und Altstadtverein stellt sich vor
}

\author{
Jürgen Schmidt
}

Wurzener Geschichtsund Altstadtverein www.geschichtsverein-wurzen.de info@geschichtsverein-wurzen.de

Präsentation der Hermann-IlgenBiografie im Plenarsaal des Wurzener Stadthauses, 2013

Feierstunde mit Gästen aus Warstein und St. Pol/Frankreich am Denkmal für die Gefallenen des Ersten Weltkriegs, 2012. Wiedereinsetzung einer Kassette mit französischer Erde von den Schlachtfeldern an der Somme.
Der Wurzener Geschichts- und Altstadt-Verein e.V. wurde am 17. Oktober 1991 gegründet. Er versteht sich als Nachfolger des 1909 gegründeten Wurzener Geschichts- und Altertumsvereins, der 1945 von der sowjetischen Besatzungsmacht aufgelöst wurde.

Dem Verein gehören in der Mehrzahl Wurzener Bürger an, die sich für den Erhalt der für die Wurzener Altstadt typischen städtebaulichen Merkmale einsetzen und die traditionsreiche Geschichte der alten meißnischen Stiftsund Bischofsstadt im Bewusstsein der Gegenwart erhalten wissen wollen.

Dazu hilft der Verein bei der Sanierung der vom Verfall bedrohten Teile der historischen Innenstadt als Partner der Stadtverwaltung und der Bürger. Damit verbunden fördert der Verein die Erforschung der Geschichte der Stadt und des Wurzener Landes, publiziert die Ergebnisse der Arbeit und veranstaltet regelmäßig Informationsveranstaltungen und thematische Stadtrundgänge.

Ausgewählte Ergebnisse der Vereinsarbeit:

- Wiedererrichtung der Wettinsäule 1996, nachdem diese zu DDR-Zeiten vergraben worden war

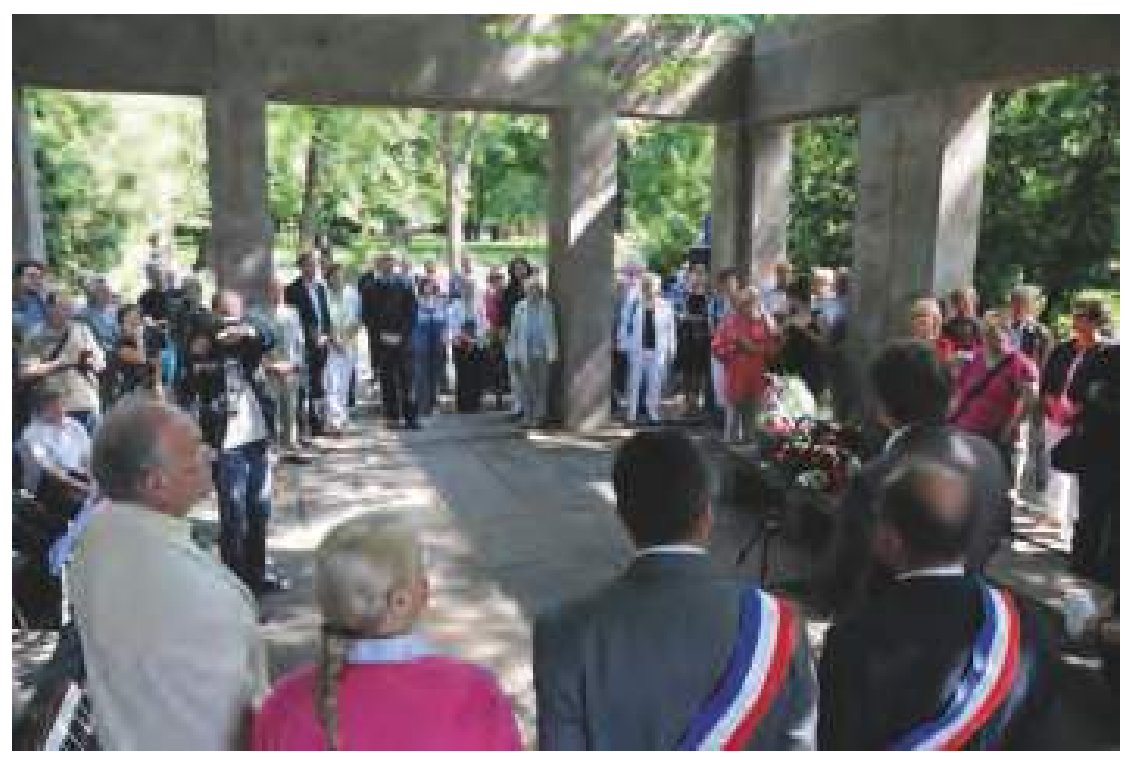

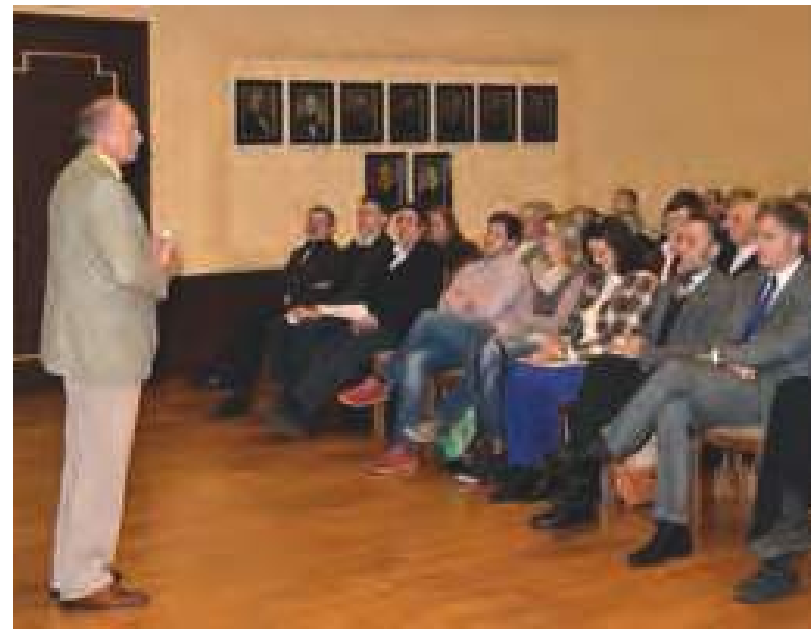

- Erneuerung des Margaretenkreuzes an der Mulde 1998

- Sanierung des Pesthäuschen auf dem alten Friedhof zu Wurzen 1999

- Planung, Finanzierung und Bau eines Stadtmodells „Wurzen 1820" für das Kulturgeschichtliche Museum der Stadt im Zeitraum 1998 bis 2006

- Sanierung der Postmeilensäule Wurzen 2009

- Komplettierung des Denkmals für die Gefallenen des Ersten Weltkrieges auf dem Alten Friedhof in einer städtepartnerschaftlichen Aktion mit Warstein/Deutschland und Saint Pol/Frankreich 2012 bis 2015

- Regelmäßige Präsentation von Objekten zum Tag des offenen Denkmals

- Gestaltung und Bau von mehreren Informationstafeln (Wappenschilder) an historischen Orten und Gebäuden der Stadt

- Gestaltung der Grabstelle des früheren Ehrenbürgers der Stadt Petter Andreas Georg Juel 2015

Darüber hinaus hat der Geschichts- und Altstadtverein zahlreiche Veröffentlichungen gefördert. Mehrere Mitglieder des Vereins haben auch an der vorliegenden Ausgabe der „Sächsischen Heimatblätter" mitgearbeitet. 